\title{
High-frequency ultrasonography (HFUS) as a useful tool in differentiating between plaque morphea and extragenital lichen sclerosus lesions
}

\author{
Rafał Białynicki-Birula, Radomir Reszke, Jacek C. Szepietowski
}

Department of Dermatology, Venereology and Allergology, Wroclaw Medical University, Wroclaw, Poland

Adv Dermatol Allergol 2017; XXXIV (5): 485-489

DOI: https://doi.org/10.5114/ada.2017.71118

\begin{abstract}
Introduction: Morphea and lichen sclerosus (LS) are chronic inflammatory diseases that may pose a diagnostic challenge for a physician. High-frequency ultrasonography (HFUS) is a versatile diagnostic method utilized in dermatologic practice, allowing monitoring the course of the disease, treatment response and differentiation between certain skin disorders.

Aim: To prove the usefulness of HFUS in differentiating between plaque morphea and extragenital LS lesions. Material and methods: We examined 16 patients with plaque morphea and 4 patients with extragenital LS using $20 \mathrm{MHz}$ taberna pro medicum ${ }^{\mathrm{TM}}$ (Germany) device.

Results: Investigations revealed hyperechogenic entrance echo in both morphea and LS lesions, whereas a distinct polycyclic surface of the entrance echo was detected exclusively in LS.

Conclusions: High-frequency ultrasonography is a current diagnostic modality that may prove useful in differentiating between morphea and LS lesions.
\end{abstract}

Key words: high-frequency ultrasonography, plaque morphea, extragenital lichen sclerosus, differentiation.

\section{Introduction}

Morphea (localized scleroderma) is a rare, chronic inflammatory disease of the skin and subcutaneous tissues that progresses to sclerosis. Typical plaque lesions are oval or round and indurated. The inflammatory stage (Figure 1) is characterised by an erythematous halo (lilac ring) [1]. The sclerotic stage (Figure 2) presents with an ivory coloured centre of the lesion. After months to years the skin becomes atrophic and soft, with areas of hypoor hyperpigmentation (Figure 3). Involvement of deeper structures (fascia, muscles, bones, nerves) may result in disability.

Lichen sclerosus (LS) is an inflammatory disease as well, affecting superficial dermis or submucosa, leading to hypopigmentation, induration and atrophy. Anogenital lesions are typical, whereas extragenital localization is less frequent, usually including the upper trunk, axillae, buttocks and lateral thighs [2]. The lesions appear as porcelain-white plaques, occasionally presenting follicular dells and ecchymoses. Pruritus, often of severe intensity, may accompany the lesions.
Morphea and LS lesions are typically distinguishable from each other basing on clinical and histological examination although occasionally diagnostic difficulties may occur [3]. Both disorders may coexist in an affected individual. Up to $38 \%$ of patients diagnosed with morphea suffer from genital LS as well [4], whereas extragenital LS was present in approximately $1.7 \%$ of patients with morphea [5].

The association between morphea and LS remains controversial. Peterson et al. [1] defined LS as a subtype of plaque morphea. Uitto et al. [3] observed clinical and histologic features of LS and morphea in the same lesions in 7 of 10 evaluated patients concluding that clinical spectrum may reflect similar etiologic events or closely related pathologic processes. Although ethiopathogenesis of these two entities is not completely understood, autoimmune processes, Borrelia burgdorferi infection or previous trauma have been proposed as common causative factors [2, 6]. Other investigators also reported coexistence of extragenital LS and morphea [7-10]. On the other hand, Patterson and Ackermann [11] deemed LS and morphea as separate clinical entities

Address for correspondence: Rafał Białynicki-Birula MD, PhD, Department of Dermatology, Venereology and Allergology, Wroclaw Medical University, 1 Chałubińskiego St, 50-368 Wroclaw, Poland, phone: +48 601990 167, fax: +48 713270942 , e-mail: rafal.bialynicki-birula@umed.wroc.pl Received: 25.06.2016, accepted: 30.08.2016. 


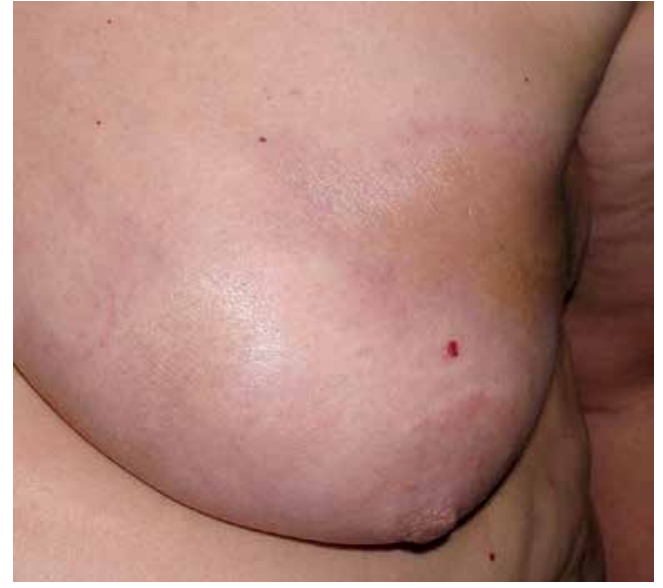

Figure 1. Inflammatory stage of morphea. Erythematous halo is prominent ("lilac ring")

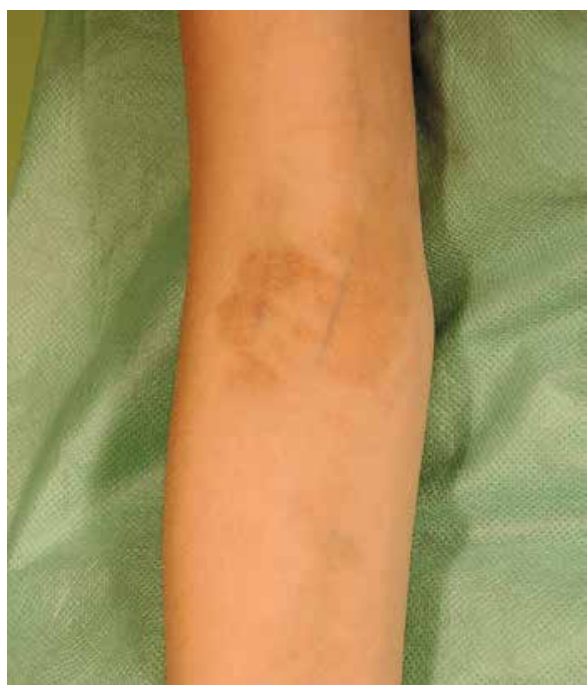

Figure 3. Atrophic stage of morphea. The skin is thin, hypoand hyperpigmentation areas are also visible

due to the observation that deeper structures (reticular dermis, subcutaneous tissue) were affected exclusively in morphea. Ensuing studies provided additional data concerning differentiation between LS and morphea [12-16].

Ultrasonography is a versatile diagnostic imaging technique aiding diagnosis in numerous medical specialties. As to dermatology, frequencies of $7.5-15 \mathrm{MHz}$ are used in evaluation of lymph nodes and subcutaneous lesions. $20 \mathrm{MHz}$ and higher frequencies (high-frequency ultrasonography - HFUS) provide physicians with an opportunity to visualize upper layers of the skin in better resolution [17]. High-frequency ultrasonography has proven useful in real time visualization of healthy and lesional skin areas without performing the biopsy. The method is rapid, non-invasive and safe but requires

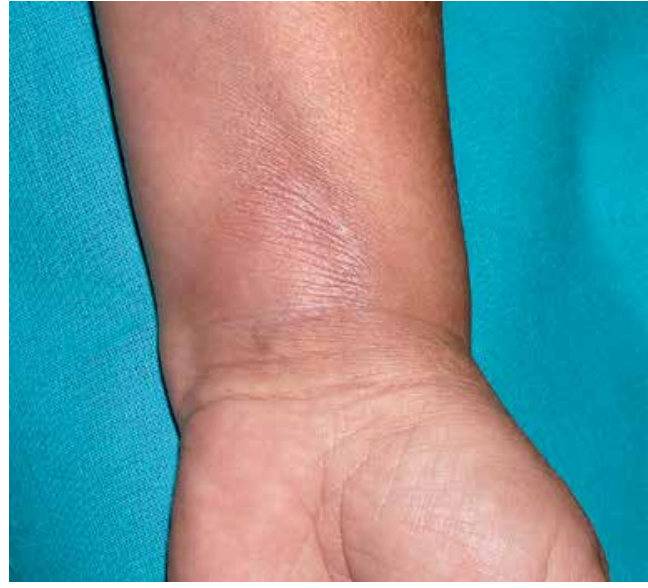

Figure 2. Sclerotic stage of morphea. Whitish plaques are firm upon palpation

special training of the physician. High-frequency ultrasonography may be utilized in evaluating the progress of several skin disorders and their response to treatment $[18,19]$. Additionally, sonographic imaging may aid differential diagnosis in certain dermatoses.

\section{Aim}

Our study attempted to establish usefulness of HFUS in differentiating between plaque morphea and extragenital LS lesions.

\section{Material and methods}

We examined 16 consecutive patients admitted to our Department of Dermatology due to plaque morphea (16 females; mean age: $35.9 \pm 14.3$ years) and 4 consecutive patients presenting extragenital LS (4 females; mean age: $55 \pm 9$ years). Each diagnosis had been previously confirmed by histological examination of skin biopsy specimens. Ultrasonographic imaging was performed utilizing $20 \mathrm{MHz}$ taberna pro medicum ${ }^{\mathrm{TM}}$ (Germany) device. The data were collected and saved using DUB mi$\mathrm{Cro}^{\oplus}$ tpm and DUB $6100 \vee 1.0$ software. The parameters of axial and lateral resolution were approximately $80 \mu \mathrm{m}$ and $200 \mu \mathrm{m}$, respectively. The length and the depth of investigation reached $12.8 \mathrm{~mm}$ and $8 \mathrm{~mm}$, respectively. Measurements and echogenicity of the structures were assessed in both A-mode and B-mode. The densitometry value was defined as the mean height of reflection amplitude, measured in a standardized colour scale of 255 amplitude levels. In B-mode images dark colours were associated with hypoechogenic structures, bright colours with hyperechogenic structures. Each subject was evaluated in lesional and corresponding contralateral healthy skin areas as well, providing a point of reference. The study was approved by the local ethics committee. 


\section{Results}

Healthy areas of the skin examined with HFUS revealed a hyperechogenic entrance echo, a normoechogenic area below (representing dermis) and a hypoechogenic or anechogenic zone associated with subcutaneous tissues (Figure 4). The border between dermis and subcutaneous tissues was linear. Linear hyperechogenic structures below represented muscle fascia.

Each patient suffering from plaque morphea (in every stage: inflammatory, sclerotic and atrophic) demonstrated a hyperechogenic entrance echo in HFUS. Examinations revealed a widened, normo- and hypoechogenic areas below in 4 cases. Upon clinical examination, lesions were indurated during palpation. Eleven patients presented a narrow hypoechogenic area depicting the fibrosing process in dermis (Figure 5). Subjects with extragenital LS presented a hyperechogenic entrance echo along with the distinct polycyclic surface. Below, a narrow hypoechogenic area was detected. The dermis area was markedly widened and hypoechogenic as well (Figure 6). Clinical details regarding each patient are summarized in Tables 1 and 2.

\section{Discussion}

High-frequency ultrasonography is a useful diagnostic modality in dermatology, which complements the diagnosis and monitoring of various disorders. Hoffmann et al. [20] and Kreuter et al. [5] reported HFUS usefulness in monitoring the course and treatment of morphea. Similar conclusions were reached by Szymanska et al. [21] who analysed both morphea and LS lesions. Chen et al. [22] described a case of a 54-year-old woman with an abdominal LS lesion resembling morphea. The HFUS implied the diagnosis of LS, further confirmed by a skin biopsy. However, the authors did not describe new ultrasonographic phenomena supporting the differential diagnosis. To our knowledge, our study is the first to report that hyperechogenic, polycyclic entrance echo is a characteristic ultrasonographic feature of LS. In clinical practice, the differential diagnosis between plaque morphea and extragenital LS lesions may occasionally pose a challenge to a dermatologist. Should doubts concerning the diagnosis arise, histological evaluation of the skin biopsy specimen is the proceeding of choice. Several authors compared histological features of morphea and LS. Rahbari [12] reported decreased or absent elastic fibers in upper dermis of LS subjects as opposed to morphea lesions. The specimens were stained with hematoxylin and eosin as well as Pinkus acid orcein. Nishioka [13] observed that collagen fibers in reticular dermis in morphea and LS are green in polarized microscopy following Picrosirius Red staining. In early stages of LS, collagen fibers in papillary dermis were orange, whereas late-stage lesions appeared green. Differences in colour were are also evident in morphea: collagen fibers just below the epidermis

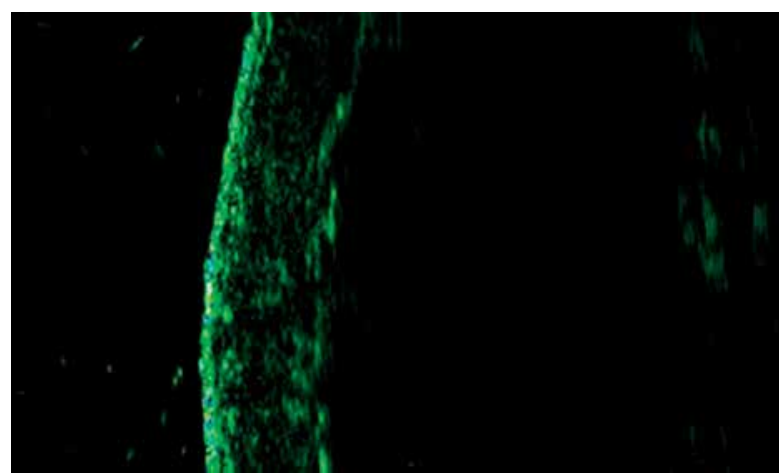

Figure 4. Typical HFUS image of healthy skin regions. On the left side of the figure, hyperechogenic entrance echo is present, followed by a normoechogenic area representing dermis (1670 $\mu \mathrm{m}$ of thickness) and a hypoechogenic or anechogenic zone associated with subcutaneous tissues

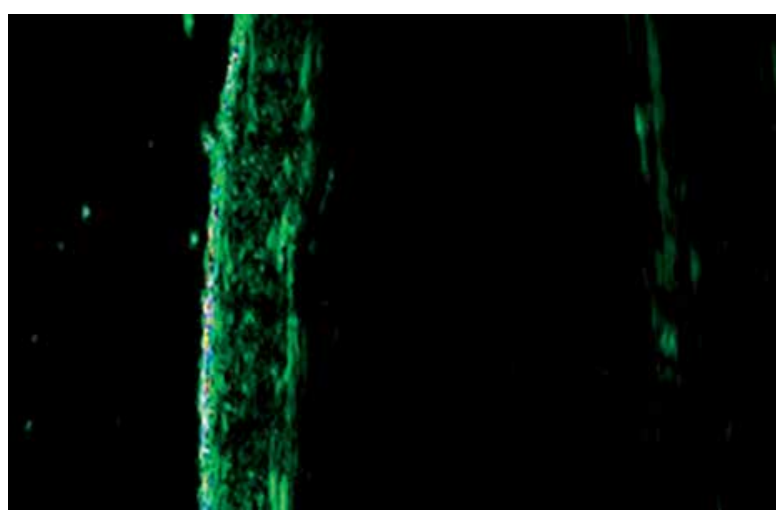

Figure 5. High-frequency ultrasonography image of a morphea lesion. Hyperechogenic entrance echo. Thin area of dermis (1200 $\mu \mathrm{m}$ vs. $1450 \mu \mathrm{m}$ in the clinically unchanged skin)

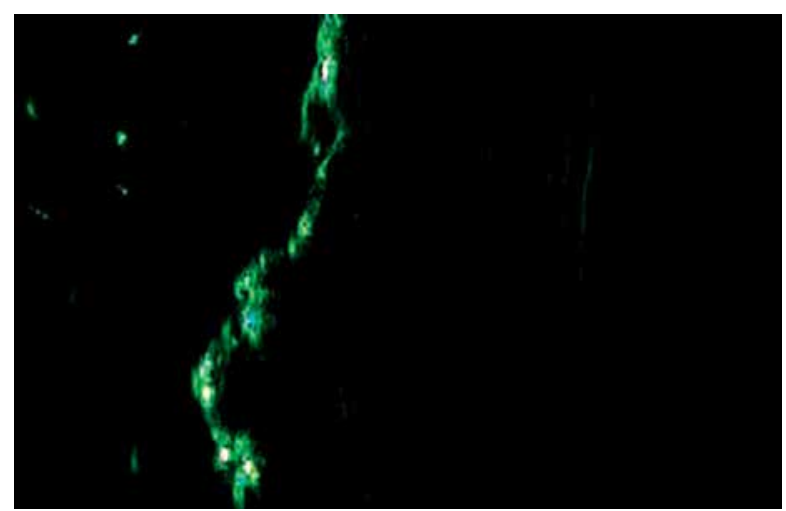

Figure 6. High-frequency ultrasonography image of an extragenital lichen sclerosus lesion. Widened, hyperechogenic and polycyclic entrance echo

were orange yellow and in the papillary dermis - green. Shono et al. [14] reported different epidermal lectin binding profiles in LS and morphea. Kowalewski et al. [15] applied histochemical staining to basement membrane 
Table 1. Clinical details of patients with plaque morphea

\begin{tabular}{|c|c|c|c|c|}
\hline Patient no. & Age & Localization & Clinical features & Ultrasonographic examination \\
\hline 1 & 24 & Thigh & Inflammatory stage & $\begin{array}{l}\text { Hyperechogenic entrance echo. Widened area of dermis } \\
(1500 \mu \mathrm{m} \text { in the lesional skin vs. } 1350 \mu \mathrm{m} \text { in the healthy skin) }\end{array}$ \\
\hline 2 & 27 & Thigh & Inflammatory stage & $\begin{array}{l}\text { Hyperechogenic entrance echo. Widened area of dermis } \\
(1750 \text { vs. } 1250 \mu \mathrm{m})\end{array}$ \\
\hline 3 & 25 & Thigh & $\begin{array}{l}\text { Advanced sclerotic } \\
\text { stage }\end{array}$ & $\begin{array}{l}\text { Hyperechogenic entrance echo. Widened, hypoechogenic area } \\
\text { of dermis ( } 2600 \mathrm{vs} .1200 \mu \mathrm{m})\end{array}$ \\
\hline 4 & 37 & Thigh & Sclerotic stage & $\begin{array}{l}\text { Hyperechogenic entrance echo. Thin, hypoechogenic area } \\
\text { of dermis ( } 860 \mathrm{vs.} 1500 \mu \mathrm{m})\end{array}$ \\
\hline 5 & 36 & Thigh & Sclerotic stage & $\begin{array}{l}\text { Hyperechogenic entrance echo. Thin, hyperechogenic area } \\
\text { of dermis ( } 850 \mathrm{vs.} 1100 \mu \mathrm{m})\end{array}$ \\
\hline 6 & 28 & Thigh & Sclerotic stage & $\begin{array}{l}\text { Hyperechogenic entrance echo. Thin, hyperechogenic area } \\
\text { of dermis ( } 850 \mathrm{vs.} 1100 \mu \mathrm{m})\end{array}$ \\
\hline 7 & 44 & Thigh & Atrophic stage & $\begin{array}{l}\text { Hyperechogenic entrance echo. Thin area of dermis } \\
(1250 \text { vs. } 1800 \mu \mathrm{m})\end{array}$ \\
\hline 8 & 27 & Arm & Atrophic stage & $\begin{array}{l}\text { Hyperechogenic entrance echo. Thin area of dermis } \\
(700 \text { vs. } 1000 \mu \mathrm{m})\end{array}$ \\
\hline 9 & 11 & Thigh & Atrophic stage & $\begin{array}{l}\text { Hyperechogenic entrance echo. Thin area of dermis } \\
(1200 \mu \mathrm{m} \text { vs. } 1450 \mu \mathrm{m}) \text { (Figure } 1)\end{array}$ \\
\hline 10 & 14 & Thigh & Atrophic stage & $\begin{array}{l}\text { Hyperechogenic entrance echo. Thin area of dermis } \\
(1200 \text { vs. } 1670 \mu \mathrm{m})\end{array}$ \\
\hline 11 & 58 & Forearm & Atrophic stage & $\begin{array}{l}\text { Hyperechogenic entrance echo. Thin area of dermis } \\
(580 \text { vs. } 800 \mu \mathrm{m})\end{array}$ \\
\hline 12 & 42 & Back & Sclerotic stage & $\begin{array}{l}\text { Hyperechogenic entrance echo. Thin, hyperechogenic area } \\
\text { of dermis (1000 vs. } 2300 \mu \mathrm{m})\end{array}$ \\
\hline 13 & 56 & Shoulder & Deep morphea & $\begin{array}{l}\text { Hyperechogenic entrance echo. Hypoechogenic, widened area } \\
\text { of dermis (1570 vs. } 1370 \mu \mathrm{m})\end{array}$ \\
\hline 14 & 53 & Shoulder & Deep morphea & $\begin{array}{l}\text { Hyperechogenic entrance echo. Hypoechogenic, widened area } \\
\text { of dermis ( } 2344 \text { vs. } 1534 \mu \mathrm{m})\end{array}$ \\
\hline 15 & 48 & Shoulder & Deep morphea & $\begin{array}{l}\text { Hyperechogenic entrance echo. Hypoechogenic, widened area } \\
\text { of dermis ( } 3400 \text { vs. } 1300 \mu \mathrm{m})\end{array}$ \\
\hline 16 & 44 & Wrist & Deep morphea & $\begin{array}{l}\text { Hyperechogenic entrance echo. Hypoechogenic, widened area } \\
\text { of dermis ( } 2300 \text { vs. } 1000 \mu \mathrm{m})\end{array}$ \\
\hline
\end{tabular}

Table 2. Clinical details of patients with extragenital LS

\begin{tabular}{ccccc}
\hline Patient no. & Age & Localization & Clinical features & Ultrasonographic examination \\
\hline 1 & 50 & Back & Elevated plaque & Widened, hyperechogenic and polycyclic entrance echo \\
\hline 2 & 54 & Back & Elevated plaque & Widened, hyperechogenic and polycyclic entrance echo (Figure 2) \\
\hline 3 & 48 & Wrist & $\begin{array}{c}\text { Slightly elevated } \\
\text { plaque }\end{array}$ & $\begin{array}{l}\text { Hyperechogenic, polycyclic entrance echo was both widened and } \\
\text { thin. Anechogenic structures below. Widened dermis area } \\
(2100 \text { vs. } 1470 \mu \mathrm{m})\end{array}$ \\
\hline 4 & 68 & Back & Blister and elevated \\
plaque & $\begin{array}{l}\text { Hyperechogenic, polycyclic entrance echo. Widened dermis area } \\
\text { (3200 vs. 2400 } \mu \mathrm{m})\end{array}$ \\
\hline
\end{tabular}

zone (BMZ) particles of biopsy specimens and performed examinations using laser scanning confocal microscopy. In morphea, the continuity of BMZ was preserved in all layers, whereas in LS, invaginations and holes were detected in lamina lucida and lamina densa. Additionally, early inflammatory stages of morphea compared with inactive stages and LS demonstrated a different vascular network. Unfortunately, the skin biopsy is invasive and ensuing histologic procedures are relatively time consuming. Therefore, new methods of differentiation have also been described. Shim et al. [16] evaluated the use of dermatoscopy which revealed fibrotic beams in 
morphea and comedo-like openings and whitish patches in LS. These features represented histologic phenomena: sclerosis in morphea, whereas follicular plugging and skin atrophy in LS.

\section{Conclusions}

Our preliminary study implies that HFUS may be useful in differentiating between plaque morphea and extragenital LS. Hyperechogenic, polycyclic entrance echo seems to be a characteristic ultrasonographic phenomenon in extragenital LS lesions, although further studies concerning this issue are necessary.

\section{Conflict of interest}

The authors declare no conflict of interest.

\section{References}

1. Peterson LS, Nelson AM, Su WP. Classification of morphea (localized scleroderma). Mayo Clin Proc 1995; 70: 1068-76.

2. Neill SM, Lewis FM, Tatnall FM, et al. British Association of Dermatologists' guidelines for the management of lichen sclerosus 2010. Br J Dermatol 2010; 163: 672-82.

3. Uitto J, Santa Cruz DJ, Bauer EA, et al. Morphea and lichen sclerosus et atrophicus. Clinical and histopathologic studies in patients with combined features. J Am Acad Dermatol 1980; 3: 271-9.

4. Lutz V, Francès C, Bessis D, et al. High frequency of genital lichen sclerosus in a prospective series of 76 patients with morphea: toward a better understanding of the spectrum of morphea. Arch Dermatol 2012; 148: 24-8.

5. Kreuter A, Wischnewski J, Terras S, et al. Coexistence of lichen sclerosus and morphea: a retrospective analysis of 472 patients with localized scleroderma from a German tertiary referral center. J Am Acad Dermatol 2012; 67: 1157-62.

6. Fett N, Werth VP. Update on morphea: part I. Epidemiology, clinical presentation, and pathogenesis. J Am Acad Dermatol 2011; 64: 217-28.

7. Tremaine R, Adam JE, Orizaga M. Morphea coexisting with lichen sclerosus et atrophicus. Int I Dermatol 1990; 29: 486-9.

8. Sawamura D, Yaguchi T, Hashimoto I, et al. Coexistence of generalized morphea with hisotological changes in lichen sclerosus et atrophicus and lichen planus. J Dermatol 1998; 25: 409-11.

9. Kim DH, Lee KR, Kim TY, et al. Coexistence of lichen sclerosus with morphoea showing bilateral symmetry. Clin Exp Dermatol 2009; 34: e416-8.

10. Chen YT, Chiang YY. Coexistence of morphea and lichen sclerosus et atrophicus in a zosteriform pattern. Dermatologica Sinica 2014; 32: 65-6.

11. Patterson JA, Ackerman AB. Lichen sclerosus et atrophicus is not related to morphea. A clinical and histologic study of 24 patients in whom both conditions were reputed to be present simultaneously. Am J Dermatopathol 1984; 6: 323-35.

12. Rahbari H. Histochemical differentiation of localized morphea-scleroderma and lichen sclerosus et atrophicus. J Cutan Pathol 1989; 16: 342-7.

13. Nishioka S. Histological comparison of morphea and lichen sclerosus et atrophicus. Kurume Med J 1997; 44: 83-90.
14. Shono S, Imura M, Ota M. Lichen sclerosus et atrophicus, morphea, and coexistence of both diseases. Histological studies using lectins. Arch Dermatol 1991; 127: 1352-6.

15. Kowalewski C, Kozłowska A, Górska M, et al. Alterations of basement membrane zone and cutaneous microvasculature in morphea and extragenital lichen sclerosus. Am J Dermatopathol 2005; 27: 489-96.

16. Shim WH, Jwa SW, Song M, et al. Diagnostic usefulness of dermatoscopy in differentiating lichen sclerous et atrophicus from morphea. J Am Acad Dermatol 2012; 66: 690-1.

17. Kleinerman R, Whang TB, Bard RL, et al. Ultrasound in dermatology: principles and applications. J Am Acad Dermatol 2012; 67: 478-87.

18. Polanska A, Danczak-Pazdrowska A, Silny W, et al. High-frequency ultrasonography in monitoring the effects of treatment of selected dermatoses. Post Dermatol Alergol 2011; 28: $255-60$

19. Olek-Hrab K, Silny W, Danczak-Pazdrowska A, et al. Ultraviolet A1 phototherapy for mycosis fungoides. Ultraviolet A1 phototherapy for mycosis fungoides. Clin Exp Dermatol 2013; 38: 126-30.

20. Hoffmann K, Gerbaulet U, el-Gammal S, et al. 20-MHz B-mode ultrasound in monitoring the course of localized scleroderma (morphea). Acta Derm Venereol Suppl (Stockh) 1991; 164: 3-16.

21. Szymanska E, Nowicki A, Mlosek K. Skin imaging with high frequency ultrasound - preliminary results. Eur J Ultrasound 2000; 12: 9-16.

22. Chen HC, Kadono T, Mimura Y, et al. High-frequency ultrasound as a useful device in the preliminary differentiation of lichen sclerosus et atrophicus from morphea. J Dermatol 2004; 31: 556-9. 